\title{
Pseudoaccommodating bifocal intraocular lens implantation in eyes with previous corneal refractive surgery - refractive outcomes: case series of 8 eyes
}

\section{Implante de lentes intraoculares pseudoacomodativas bifocais em olhos com cirurgia refrativa corneana prévia - resultados refracionais: série de casos de 8 olhos}

Giuliano de Oliveira Freitas, M.D. ${ }^{1}$, Natália de Oliveira Faria, M.D. ${ }^{2}$, Joel Edmur Boteon, M.D., Ph.D. ${ }^{3}$, Mario José Carvalho, M.D. ${ }^{4}$

ABSTRACT
Objective: Accurate intraocular lens power calculation may be a challenging issue in
eyes with previous corneal refractive surgery. Methods: The authors present a series of 8
eyes (4 previously submitted to hyperopic laser in situ keratomileusis and 4 to radial
keratectomy) submitted to phacoemulsification and implantation of
pseudoaccommodating bifocal intraocular lens. Double-KSRK/Tformula has been used.
Results: Acceptable refractive visual outcomes have been achieved. Conclusion:
Pseudoaccommodating bifocal intraocular lenses can be safely implanted in patients
with previous corneal refractive surgery.

Keywords: Phacoemulsification/surgery; Lens implantation, intraocular; Cornea/surgery; Biometry; Refraction, Ocular

\footnotetext{
${ }^{1}$ Postgraduate Student (Doctorate Degree) at Universidade Federal de Minas Gerais - UFMG - Belo Horizonte (MG), Brazil; Member of Cataract Surgery staff at Instituto de Saúde Ocular - ISO - Uberlândia (MG), Brazil;

${ }^{2}$ Assistant researcher at Instituto de Saúde Ocular - ISO - Uberlândia (MG), Brazil;

${ }^{3}$ Associate Professor of Ophthalmology Department at Universidade Federal de Minas Gerais - UFMG - Belo Horizonte (MG), Brazil;

${ }^{4} \mathrm{Head}$ of Cataract Surgery staff at Instituto de Saúde Ocular- ISO - Uberlândia (MG), Brazil.
}

Recebido para publicação em: 27/4/2010 - Aceito para publicação em 9/8/2010 


\section{INTRODUCTION}

$\mathbf{B}$ ifocal intraocular lenses (IOLs) provide spectacle and contact lens independence for near and far vision to a considerable number of patients submitted to phacoemulsification. Factors such as patients' unrealistic expectations, topographic astigmatism greater than 1.00 cylinder diopter (D) and previous corneal refractive surgery are considered minor - although, not negligible - contraindications to bifocal IOL implantation. Most of these factors have been extensively debated in current literature. Previous corneal refractive surgery has gained increasingly interest due to the number of patients willing to keep their spectacle or contact lenses independence, in spite of their presbyopia or age-related cataract ${ }^{(1,2)}$.

Bifocal IOL implantation in these patients may be a challenging issue, because of inaccurate biometric calculations by standard formulas, what often leads to inappropriate lens power selection and higher incidence of unintentional residual ametropia(3). Photic phenomena, inherent both to corneal refractive surgery and to bifocal IOLs, also raise concerns about visual outcomes in these patients.

Proposed solutions to lens power selection in these cases can be divided into two classes as follows: first, procedures requiring patient historical data, such as prerefracitve surgery keratometric readings (K-readings), amount of ametropia corrected or both; and second, methods relying only on current measurements. An important member of the first class is the refractive history method, which serves as a gold standard ${ }^{(1)}$. Currently, the most widely used method for keratometric calculation after refractive surgery. However, this method alone does not fully eliminate unwanted results, although their magnitude is less ${ }^{(4)}$.

We present a case series of eight eyes with previous refractive surgery submitted to phacoemulsification and bifocal IOL implantation, emphasizing postoperative uncorrected both near and distance visual acuities and patients' overall satisfaction.

\section{Methods}

In this retrospective non-comparative review of 4 consecutive patients (comprising 8 eyes) the database from "ISO Olhos - Instituto de Saúde Ocular" was searched for patients who had previous corneal refractive surgery and consecutive phacoemulsification with ReSTOR SN6AD3 IOL implantation.
Patients undergone a routine ophthalmologic examination, including measurements of their uncorrected visual acuity (UCVA), manifest refraction, best spectacle corrected distance visual acuity (BSCVA), slitlamp biomicroscopy, Goldman's applanation tonometry, and binocular indirect ophthalmoscopy through a dilated pupil. Keratometric readings were obtained from Orbscan II (Bausch\&Lomb) sim-K's. Axial length was measured using the OcuScan (Alcon) immersion mode A scan. Aramberri's double-K method with the SRK/T formula was used for IOL power calculation. Emmetropia was the target refraction.

All surgeries were performed by the same experienced surgeon (M.C.) under topical anesthesia through a $2.2 \mathrm{~mm}$ clear corneal incision. Phacoemulsification was performed using the Infiniti Vision System (Alcon) and followed by AcrySof ReSTOR SN6AD3 IOL implantation within the capsular bag. The time interval between the 2 surgeries was 7 days. Routine postoperative antiinflammatory and antibiotic medications were used for 4 weeks. Patients were scheduled for clinical evaluation 1 day, 1 week, and 1 and 6 months postoperatively. The postoperative outcomes analyzed were: distance UCVA, near uncorrected visual acuity, manifest refraction and its spherical equivalent and also BSCVA ${ }^{(2)}$. Eventual patients' complaints were taken into consideration on patients' charts.

\section{ResUlts}

\section{Preoperative demographics}

From july 2006 to august 2008, 4 patients with previous corneal refractive surgeries on both eyes: 2 hyperopic laser in situ keratomileusis (LASIK) patients and 2 radial keratotomy (RK) patients were identified as having had phacoemulsification followed by ReSTOR SN6AD3 IOL implantation on both eyes - comprising 8 eyes enrolled in this case series. There were 3 women and $1 \mathrm{man}$. The mean age was 57.5 years (ranging from 48 to 66 years, standard deviation of 7.42 years). Two of 4 patients had pre corneal refractive surgery K-readings on their charts, although Aramberri's Double-K SRK/T formula was used for all cases.

\section{Pre-phacoemulsifcation status}

Among eyes previously submitted to hyperopic LASIK, UCVA was LogMAR 0.30 for all patients; BSCVA ranged from LogMAR 0.10 to 0.00 (mean 0.05 \pm 0.06 ). The range of spherical refraction was $+0.50 \mathrm{D}$ to $+1.50 \mathrm{D}$ (mean $1.06 \mathrm{D} \pm 0.22 \mathrm{D}$ ). The mean spherical 
Table 1

Preoperative data of patients with previous refractive surgery submitted to phacoemulsification and bifocal pseudoaccommodating IOL implantation

\begin{tabular}{|c|c|c|c|c|c|c|}
\hline \multicolumn{7}{|c|}{ Data } \\
\hline $\begin{array}{l}\text { Refractive } \\
\text { Surgery }\end{array}$ & $\begin{array}{c}\text { UCVA } \\
\text { (LogMAR) }\end{array}$ & $\begin{array}{c}\text { BSCVA } \\
(\operatorname{LogMAR})\end{array}$ & $\begin{array}{c}\text { Sph. } \\
\text { (Diopters) }\end{array}$ & $\begin{array}{c}\text { MSE } \\
\text { (Diopters) }\end{array}$ & $\begin{array}{c}\text { TC } \\
\text { (Diopters) }\end{array}$ & $\begin{array}{c}\mathbf{A L} \\
\text { (Milimeters) }\end{array}$ \\
\hline \multicolumn{7}{|l|}{ Hyperopic } \\
\hline \multicolumn{7}{|l|}{ LASIK } \\
\hline Range & $\begin{array}{c}0.30 \\
\text { (All eyes) }\end{array}$ & 0.10 to 0.00 & +0.50 to +1.50 & +0.50 to +1.25 & 0.10 & 22.68 to 23.48 \\
\hline \multicolumn{7}{|l|}{ Mean \pm SD } \\
\hline & & $0.05 \pm 0.06$ & $+1.06 \pm 0.22$ & $+0.88 \pm 0.22$ & $0.70 \pm 0.22$ & $23.10 \pm 0.42$ \\
\hline \multicolumn{7}{|c|}{ 年 } \\
\hline Range & 0.60 to 0.18 & $\begin{array}{c}0.10 \\
\text { (All eyes) }\end{array}$ & +0.50 to +2.50 & +0.50 to +2.25 & 1.00 & 23.93 to 24.82 \\
\hline \multicolumn{7}{|l|}{ Mean \pm SD } \\
\hline & $0.36 \pm 0.21$ & & $+1.38 \pm 0.43$ & $+1.20 \pm 0.32$ & $0.70 \pm 0.22$ & $24.40 \pm 0.46$ \\
\hline
\end{tabular}

Table 2

Postoperative outcomes of patients with previous refractive surgery submitted to phacoemulsification and bifocal pseudoaccommodating IOL implantation

\begin{tabular}{|c|c|c|c|c|}
\hline \multicolumn{5}{|c|}{ Outcomes } \\
\hline Refractive Surgery & $\begin{array}{c}\text { UCVA } \\
(\operatorname{LogMAR})\end{array}$ & $\begin{array}{c}\text { BSCVA } \\
(\operatorname{LogMAR})\end{array}$ & $\begin{array}{c}\text { Sph. } \\
\text { (Diopters) }\end{array}$ & $\begin{array}{c}\text { MSE } \\
\text { (Diopters) }\end{array}$ \\
\hline \multicolumn{5}{|l|}{ Hyperopic LASIK } \\
\hline Range & 0.30 to 0.10 & $\begin{array}{c}0.10 \\
\text { (All eyes) }\end{array}$ & -0.50 to +0.75 & -0.75 to +0.50 \\
\hline $\begin{array}{l}\text { Mean } \pm \text { SD } \\
\text { RK }\end{array}$ & $0.15 \pm 0.10$ & & $-0.20 \pm 0.13$ & $-0.38 \pm 0.14$ \\
\hline Range & 0.18 to 0.10 & $\begin{array}{c}0.10 \\
\text { (All eyes) }\end{array}$ & -1.00 to Plano & -1.00 to +0.25 \\
\hline Mean \pm SD & $0.14 \pm 0.05$ & & $+0.50 \pm 0.41$ & $+0.13 \pm 0.43$ \\
\hline
\end{tabular}

equivalent ranged from +0.50 to $+1.25 \mathrm{D}$ (mean +0.88 $\mathrm{D} \pm 0.22 \mathrm{D})$. The maximum topographic cylinder was $1.10 \mathrm{D}$ (mean $0.70 \pm 0.22 \mathrm{D})$. Axial length $(\mathrm{AL})$ ranged from $22.68 \mathrm{~mm}$ to $23.48 \mathrm{~mm}$ (mean $23.10 \pm 0.42 \mathrm{~mm}$ ).

Among eyes previously submitted to RK, UCVA ranged from LogMAR 0.60 to 0.48 (mean $0.54 \pm 0.09$ ); BSCVA was LogMAR 0.40 to 0.18 (mean $0.29 \pm 0.16$ ). The range of spherical refraction was $+0.50 \mathrm{D}$ for both eyes. The mean spherical equivalent was also $+0.50 \mathrm{D}$ for both eyes. The maximum topographic cylinder was $1.00 \mathrm{D}$ (average $0.85 \pm 0.22 \mathrm{D}$ ). Axial length ranged from $24.77 \mathrm{~mm}$ to $24.82 \mathrm{~mm}$ (mean $24.78 \pm 0.04 \mathrm{~mm}$ ).

Table 1 summarizes the main preoperative data reported above.

\section{Postoperative analysis}

Those eyes previously submitted to hyperopic LASIK, presented UCVA ranging from LogMAR 0.30 
to 0.10 (mean $0.15 \pm 0.10$ ); BSCVA was LogMAR 0.10 for all these patients. The range of spherical refraction was $-0.50 \mathrm{D}$ to $+0.75 \mathrm{D}$ (mean $-0.20 \mathrm{D} \pm 0.13 \mathrm{D}$ ). The mean spherical equivalent ranged from -0.75 to $+0.50 \mathrm{D}$ (mean $-0.38 \mathrm{D} \pm 0.14 \mathrm{D})$.

Within a six-month postoperative follow up period for the RK patients, the UCVA ranged from LogMAR 0.18 to 0.10 (mean $0.14 \pm 0.05$ ); BSCVA was LogMAR 0.10 for all these patients. The range of spherical refraction was $-1.0 \mathrm{D}$ to plano (average $-0.50 \mathrm{D} \pm 0.41$ D). The mean spherical equivalent ranged from -1.00 to $+0.25 \mathrm{D}$ (average $+0.13 \mathrm{D} \pm 0.43 \mathrm{D}$ ).

After six months of follow up, postoperative manifest spherical refraction ranged within $\pm 1.00 \mathrm{D}$ of the intended refraction for all eyes, in accordance to current literature for monofocal IOLs virgin eyes ${ }^{(1,4)}$. Post operative UCVA, BCSVA and manifest spherical equivalent also were within an acceptable range ${ }^{(5)}$. Table 02 summarizes the postoperative outcomes above mentioned.

Both patients previously submitted to hyperopic LASIKs and the patient submitted to RK achieved uncorrected near vision of Jeager 1 consecutively to bifocal IOLs implantation.

All patients expressed subjective improvement in their overall quality of vision after surgery and described reduced dependence on spectacles. There were no intraoperative, nor postoperative complications.

\section{Discussion}

Ophthalmologists are significantly challenged by the expectations of patients associated with any form of refractive surgery; the challenge becomes even greater when former refractive surgery patients require cataract surgery. The paradox is that, as a group, post-refractive surgery patients usually have unrealistic goals for the exactness of the refractive results after cataract surgery, although their outcomes have been less predictable than in routine eyes ${ }^{(4)}$.

Multiple methods have been proposed in attempt to predict the true corneal power in eyes after refractive surgery. None has yet proven to be the most accurate in all cases ${ }^{(6)}$.

In the literature on IOL calculation after corneal refractive surgery, the major problem is the comparatively small number of patients for which the refractive outcomes after cataract surgery are available ${ }^{(1)}$. Most of the recent studies discuss "no-history" approach as the gold standard method; efforts have been focused on calculations after
LASIK or photorefractive keratectomy (PRK), literature on IOL power calculation after RK is relatively scarce and most of it, was published before the advent of the "double-K" modification of modern IOL formulas suggested by Aramberri in $2003^{(4)}$.

Modern theoretic formulas use the input of corneal power for two purposes: the first one is to predict the ultimate position of the IOL (i.e., ELP), and the second reason is - along with AL measurement, target refraction and ELP - to calculate the power of the IOL ${ }^{(7)}$. The formulations and algorithms used to predict the ELP are based on the anatomy of the anterior segment, which is not changed by corneal refractive surgery (only the center is flattened and thinned). Therefore, if the postoperative refractive surgery K-reading (which is flatter) is used to calculate the ELP, it will produce an erroneous ELP value. Because the anatomy has not changed, Aramberri recommends the use, whenever possible, of the preoperative K-reading to calculate the ELP ${ }^{(4)}$. The IOL power is then calculated using the postoperative $\mathrm{K}$-reading, thus the use of $2 \mathrm{~K}$-readings, hence "double$\mathrm{K}$ ". The use of a standard normal K-reading in the double-K method $(43.50 \mathrm{D}$ or $44.00 \mathrm{D})$ is a great improvement over using the calculated very flat Kreading if preoperative $\mathrm{K}$-reading is not available ${ }^{(7)}$. Haigis' formula is an exception to this rule ${ }^{(1)}$.

Most IOL power calculation formulas are based on standard vergence equations, and the K-readings inserted into these formulas represent the corneal power measurement obtained by keratometry or by topography. Most keratometers and topography units use a conventional index of refraction to convert the measured radius of curvature of the anterior corneal surface to a total corneal dioptric power. This index is based on an assumed fixed ratio between the front and back curvatures of the cornea. After refractive surgery, such as LASIK, this ratio is altered, introducing an error in the measurement of the corneal power. In other words, the measured post-refractive surgery K-readings do not represent the correct $\mathrm{K}$-values needed for accurate IOL power calculation in these cases.

Even with complete historical information, central topography, and high-precision biometry, cataract surgery in post-refractive eyes is often haphazardly unpredictable in its refractive outcomes and errors in excess of $2.00 \mathrm{D}$ to $3.00 \mathrm{D}$ are often encountered ${ }^{(7)}$. Intraocular lens power calculations in eyes that have had previous myopic refractive surgery underestimate the IOL power for emmetropia, resulting in a high 
incidence of unintentional postoperative hyperopia, because of altered corneal geometry. Conversely, after laser refractive surgery for hyperopia, this could result in underestimation of keratometric readings, overestimation of the IOL power required, and myopic outcomes after phacoemulsification ${ }^{(3)}$.

Techniques bypassing corneal power and axial length measurements were recently described. After cataract removal, the aphakic eye can be refracted in the operating room to calculate the IOL power needed for emmetropia. The major disadvantage of this technique is the interruption of the surgical procedure. Although early results are promising, this method is not gaining popularity among most surgeons ${ }^{(1)}$.

In our series of patients, postoperative UCVA, BSCVA and manifest spherical refraction outcomes were comparable to those expected for monofocal IOLs implanted in virgin eyes ${ }^{(5)}$. All patients achieved spectacle independence for near and far vision.

Another major concern about patients with previous corneal refractive surgery: "night visual symptoms", such as glare, halos and starbursts are commonly associated with LASIK, PRK or RK patients (8). Collectively known as "photic phenomena", these subjective complaints are similar to those ones often associated to multifocal intraocular lenses ${ }^{(9)}$. To our knowledge, there is no article in current literature addressing a theoretical worsening of photic phenomena among patients with previous corneal refractive surgery submitted to phacoemulsification and multifocal IOL implantation. Our series of patients reported no worsening, nor improvement of these symptoms.

People who have corneal refractive surgery do so to avoid the need for spectacles or contact lenses; therefore, when they develop presbyopia or agerelated cataract, they would likely prefer to remain independent of these forms of correction ${ }^{(2)}$. Once these patients tolerate well photic phenomena related to their previous refractive surgeries, it sounds reasonable that they probably will tolerate multifocal IOL photic phenomena as well, what makes these patients potential candidates for multifocal IOL implantation, broadening its indications. If an unacceptable refractive outcome is unintentionally obtained, inspite of all efforts to avoid it, excimer laser refractive surgery can be a safe and effective surgical method to enhance residual ametropia correction after cataract extraction with IOL implantation, even in eyes with previous corneal procedures ${ }^{(10)}$.

\section{Conclusion}

As shown by our series of patients, pseudoaccommodating bifocal IOLs can be safely implanted in patients with previous corneal refractive surgery. The double-K modification for third generation biometric formulas provide reasonably predictable IOL power calculations within a range near that achieved in virgin eyes.

Subjective complaints associated to multifocal IOLs are essentially the same as those for corneal refractive surgery and they do not seem to get worse when both previous refractive surgery and multifocal IOL implant coexist.

Post-phacoemulsification laser enhancement procedures may be an option for those cases in which the refractive outcomes are unacceptable.

\section{Resumo}

Objetivo: $O$ cálculo preciso do poder da lente intraocular em olhos com cirurgia refrativa prévia é, por vezes, desafiador. Métodos: Os autores apresentam uma série de casos totalizando 8 olhos (4 previamente submetidos a "laser in situ keratomileusis" hipermetrópico e 4 à ceratotomia radial) submetidos à facoemulsificação com implante de lente intraocular pseudoacomodativa bifocal. Foi empregada a fórmula "double-K" SRK/T para esses casos. Resultados: Resultados refracionais satisfatórios foram obtidos. Conclusão: Lentes intraoculares bifocais pseudoacomodativas podem ser implantadas com boa previsibilidade em pacientes com cirurgia ceratorrefrativa prévia.

Descritores: Facoemulsificação; Implante de lente intraocular; Córnea/cirurgia; Biometria; Refração ocular

\section{RefERENCES}

1. Haigis W. Intraocular lens calculation after refractive surgery for myopia: Haigis-L formula. J Cataract Refract Surg. 2008;34(10):1658-63. Comment in: J Cataract Refract Surg. 2009;35(9):1650; author reply 1650-1.

2. Fernández-Vega L, Madrid-Costa D, Alfonso JF, Montés-Micó R, Poo-López A. Optical and visual performance of diffractive intraocular lens implantation after myopic laser in situ keratomileusis. J Cataract Refract Surg. 2009;35(5):825-32.

3. Feiz V, Mannis MJ. Intraocular lens power calculation after corneal refractive surgery. Curr Opin Ophthalmol. $2004 ; 15(4): 342-9$ 
4. Aramberri J. Intraocular lens power calculation after corneal refractive surgery: double-K method. J Cataract Refract Surg. 2003;29(11):2063-8. Comment in: J Cataract Refract Surg. 2004;30(12):2458; author reply 2458-9. J Cataract Refract Surg. 2005;31(2):254-5; author reply 255-6.

5. Tzelikis PF, Akaishi L, Trindade FC, Boteon JE. Ocular aberrations and contrast sensitivity after cataract surgery with AcrySof IQ intraocular lens implantation: Clinical comparative study. J Cataract Refract Surg. 2007;33(11):1918-24.

6. Awwad ST, Dwarakanathan S, Bowman RW, Cavanagh HD, Verity SM, Mootha VV, McCulley JP. Intraocular lens power calculation after radial keratotomy: estimating the refractive corneal power. J Cataract Refract Surg. 2007;33(6):1045-50.

7. Hoffer KJ. Intraocular lens power calculation after previous laser refractive surgery. J Cataract Refract Surg. 2009;35(4):759-65. Comment in: J Cataract Refract Surg. 2009;35(12):2176; author reply 2176. J Cataract Refract Surg. 2009;35(9):1653.
8. Ang EK, Couper T, Dirani M, Vajpayee RB, Baird PN. Outcomes of laser refractive surgery for myopia. J Cataract Refract Surg. 2009;35(5):921-33.

9. Woodward MA, Randleman JB, Stulting RD. Dissatisfaction after multifocal intraocular lens implantation. J Cataract Refract Surg. 2009;35(6):992-7.

10. Kuo IC, O'Brien TP, Broman AT, Ghajarnia M, Jabbur NS. Excimer laser surgery for correction of ametropia after cataract surgery. J Cataract Refract Surg. 2005;31(11):2104-10.

\section{Corresponding author:}

Giuliano de Oliveira Freitas

R. Eduardo Marquez 50 - B. Martins

CEP 38400-442 - Uberlândia (MG), Brazil

Phone: +55 (34) 3230-5050

Fac Simile: +55 (34) 3230-5055

E-mail: gofreitas@ufmg.br 